\title{
Right ventricular to pulmonary artery conduit instead of modified Blalock-Taussig shunt improves postoperative hemodynamics in newborns after the Norwood operation
}

\author{
Rudolf Mair, MD \\ Gerald Tulzer, MD ${ }^{\mathrm{b}}$ \\ Eva Sames, MD \\ Roland Gitter, MD ${ }^{\mathrm{b}}$ \\ Evelyn Lechner, $M D^{\mathrm{b}}$ \\ Jürgen Steiner, $M D^{b}$ \\ Anna Hofer, MDc \\ Gertraud Geiselseder, MD ${ }^{\mathrm{c}}$ \\ Christoph Gross, MD
}

See related editorial on page 1268.
Objective: Perioperative mortality, prolonged postoperative recovery after the Norwood procedure, and mortality between stage I and stage II might be related to shunt physiology. A right ventricular to pulmonary artery conduit offers a banded physiology in contrast to a Blalock-Taussig shunt. The purpose of this study was to assess the hemodynamic differences and their consequences in the postoperative course between Norwood patients with a Blalock-Taussig shunt and those with a right ventricular to pulmonary artery conduit.

Methods: From October 1999 until May 2002, 32 unselected consecutive patients underwent a Norwood procedure at the General Hospital Linz. The first 18 patients received a Blalock-Taussig shunt. In the remaining 14 patients we performed a right ventricular to pulmonary artery conduit. Both groups were compared.

Results: The diastolic blood pressure was significantly higher in the right ventricular to pulmonary artery conduit group $(P<.001)$. Despite a higher $\mathrm{FIO}_{2}, \mathrm{Po}_{2}$ levels tended to be lower in the first 5 postoperative days. At the age of 3 months, catheterization laboratory data showed a lower $\mathrm{Qp} / \mathrm{Qs}$ ratio in the same group $(0.86[0.78 ; 1]$ versus 1.55 $[1.15 ; 1.6] ; P=.005)$ and a higher $\mathrm{dp} / \mathrm{dt}(955[773 ; 1110]$ vs $776[615 ; 907] ; P=.018)$. (Descriptive data reflect medians and quartiles [in brackets].) Hospital survival was $72 \%$ in the Blalock-Taussig shunt group versus $93 \%$ in the right ventricular to pulmonary artery conduit group. Mortality between stage I and stage II was $23 \%$ in the Blalock-Taussig shunt group versus $0 \%$ in the right ventricular to pulmonary artery conduit group.

Conclusions: A higher diastolic blood pressure and a lower Qp/Qs ratio were associated with a more stable and efficient circulation in patients with a right ventricular to pulmonary artery conduit. More intensive ventilatory support was necessary during the first postoperative days. We did not note any adverse effects of the ventriculotomy on ventricular performance.

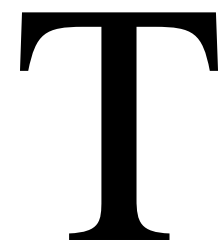

he Norwood procedure is widely used as initial palliation for hypoplastic left heart syndrome and univentricular hearts with systemic outflow tract obstruction. ${ }^{1}$ Although in selected centers the results of the Norwood operation are outstanding, accepted survival rates are still behind those of biventricular reconstructive procedures in newborns and those of non-pump palliations in univentricular hearts. ${ }^{2}$ Postoperative recovery after deep hypothermic circulatory arrest is often prolonged, 
delayed chest closure is still standard, and mortality between hospital discharge and stage II is remarkable. ${ }^{3}$

Some of these problems can be related to the BlalockTaussig (BT) shunt physiology with diastolic runoff. The resulting low diastolic blood pressure might worsen coronary, cerebral, intestinal, and renal perfusion. This increases the risk for heart failure, cerebral injury, necrotizing enterocolitis, and renal failure. Large BT shunts can lead to congestive heart failure due to a high $\mathrm{Qp} / \mathrm{Qs}$ ratio. ${ }^{4}$

A nonvalved right ventricular to pulmonary artery (RVPA) conduit avoids diastolic runoff. Therefore, diastolic blood pressure should be higher and systemic perfusion should be improved. ${ }^{5}$ Because pulmonary perfusion occurs only in systole, the Qp/Qs ratio should be lower in these patients. The placement of an RV-PA conduit requires a ventriculotomy in an univentricular heart with unclear short- and long-term effects.

The objective of this study was to assess the differences in hemodynamics between newborns after Norwood procedures with BT shunts and RV-PA conduits.

\section{Patients and Methods \\ Patients}

From October 1999 until May 2002, 32 unselected consecutive patients underwent a Norwood procedure for either hypoplastic left heart syndrome or single ventricle with systemic outflow tract obstruction. No anatomic, metabolic, or other selection criteria were applied to the patients.

The first 18 patients received a BT shunt (group 1). In July 2001 we changed the operative procedure and performed an RV-PA conduit in the last 14 patients. All other technical details remained the same. So 2 comparable groups of patients resulted. Differences between both groups concerning age, weight, and diagnoses could be due to chance (Table 1).

Informed consent was obtained from the parents of each patient about all details of the operative procedure.

\section{Operative Procedure}

A classic or modified Norwood procedure was done in all patients, maintaining continuous antegrade cerebral perfusion. In all cases we used double arterial cannulation (main pulmonary artery and brachiocephalic artery via a 3.5- or 3-mm polytetrafluoroethylene [PTFE; Gore-Tex; W. L. Gore \& Associates, Inc, Flagstaff, Ariz] prosthesis) and single venous cannulation.

In the BT shunt group the pulmonary artery was divided and the distal part closed by direct suture. In the RV-PA conduit group the pulmonary artery was divided and the distal part of it connected to a 5-mm PTFE conduit.

The aortic arch augmentation was done under continuous antegrade cerebral perfusion at a flow rate of $30 \mathrm{~mL} / \mathrm{kg}$ and a rectal temperature of $22^{\circ} \mathrm{C}$.

A homograft patch was used in all patients with normally related great arteries. In patients with transposition of the great arteries, usually a direct anastomosis between aortic arch, descending aorta, and main pulmonary artery could be performed. The ascending aorta was then connected separately to the main pulmonary artery.

Circulatory arrest was restricted to the excision of the atrial septum. The 3.5-mm PTFE prosthesis, which was used as the cannulation site, became the BT shunt. In the RV-PA conduit group the anastomosis between conduit and RV outflow tract was performed during rewarming on the fibrillating heart. A ventriculotomy was made in the infundibulum of the right ventricle over a length of about $10 \mathrm{~mm}$ and a direct anastomosis was performed. The 3.5-mm prosthesis, used for arterial cannulation, was removed at the end of the operation.

\section{Operative Parameters}

The groups showed no important differences in total bypass time (BT shunt: 188 minutes [174; 205]; RV-PA conduit: 179 minutes [164; 199], $P=.494$ ), period of antegrade cerebral perfusion (BT shunt: 57 minutes [53; 69]; RV-PA conduit: 59 minutes [49; 62], $P=.493$ ), and circulatory arrest $(P=1)$. (Unless otherwise mentioned, descriptive data in the text reflect medians and quartiles [in brackets].)

All operations were done by the same surgical team. The chest was routinely left open in all patients of the BT shunt group and was closed primarily in 7 of the last 8 patients of the RV-PA conduit group. Our decision to close the chest primarily was based on our favorable experience with the first 6 patients.

\section{Follow-up}

In the intensive care unit (ICU), all patients were under continuous monitoring by electrocardiogram for arterial pressure, atrial pressure, pulsoxymetry, and end-tidal $\mathrm{CO}_{2}$. Urine output was collected hourly and blood gas analysis was done in 2- to 3-hour intervals. Repeated echocardiogram studies were performed by pediatric cardiologists routinely to rule out anatomic problems and pericardial or pleural effusions if suspected. Patients were discharged as soon as they could be managed (usually feeding) by their parents. All patients routinely got a bidirectional Glenn shunt 3 months after stage I. One to 2 days prior to the bidirectional Glenn procedure, a catheterization laboratory study was undertaken in all patients.

Pulmonary artery pressure, pulmonary vascular resistance, $\mathrm{Qp} / \mathrm{Qs}$ ratio, and dp/dt were measured or calculated. The postoperative anatomy was carefully examined and residual problems interventionally treated, if possible.

\section{Data Collection and Analysis}

Data were collected from patients' records and catheterization laboratory reports (Table 2). The following hemodynamic parameters were examined during the first 5 days at the ICU:

Systolic and diastolic blood pressure, left atrial pressure: Mean values were calculated over 24 hours from hourly recorded pressures.

Urine output: Mean values were calculated from hourly urine output per kilogram of body weight.

Decrease in serum lactate levels: Postoperative hours till serum lactate level was less than $2 \mathrm{mmol} / \mathrm{L}$ were measured.

Further parameters examined in this field were: 
Table 1. Patients

\begin{tabular}{|c|c|c|c|c|c|c|}
\hline & No. & Age (d) & Weight (kg) & Anatomy & Preop procedure & Mortality \\
\hline \multirow[t]{18}{*}{ BT shunt } & 1 & 4 & 3.3 & MA/AA & & \\
\hline & 2 & 9 & 3.2 & MS/AS & & \\
\hline & 3 & 19 & 3.6 & MS/AS, restrictive PFO & Rashkind & \\
\hline & 4 & 5 & 2.8 & MS/AA & & \\
\hline & 5 & 8 & 4.2 & MS/AA & Rashkind & $\dagger$ \\
\hline & 6 & 10 & 2.8 & $\mathrm{MA} / \mathrm{AA}$ & & $\dagger$ \\
\hline & 7 & 6 & 2.7 & MA/AA & & \\
\hline & 8 & 9 & 2.7 & MA/AA & & $\dagger$ \\
\hline & 9 & 4 & 3.7 & MS/AS & & \\
\hline & 10 & 20 & 3.8 & MS/AS & & $\dagger$ \\
\hline & 11 & 4 & 3.1 & MA/AA & & \\
\hline & 12 & 5 & 3.5 & $\mathrm{MA} / \mathrm{AA}, \mathrm{TAPVC}$ & & \\
\hline & 13 & 7 & 2.7 & MA/AA & & \\
\hline & 14 & 2 & 3.1 & MS/AA & & \\
\hline & 15 & 4 & 2.9 & MS/AA & & $\dagger$ \\
\hline & 16 & 57 & 2.9 & MS/AS, multiple VSDs & & \\
\hline & 17 & 7 & 4.2 & $\begin{array}{l}\text { SV, SLL-TGA, restrictive } \\
\text { VSD, hypoplastic } \\
\text { aortic arch }\end{array}$ & & \\
\hline & 18 & 8 & 3.6 & $\begin{array}{l}\text { SV, SLL-TGA, restrictive } \\
\text { VSD, hypoplastic } \\
\text { aortic arch }\end{array}$ & & \\
\hline Median (quartile) & & $7[4 ; 9]$ & $3.2[2.8 ; 3.6]$ & & & \\
\hline \multirow[t]{14}{*}{ RV-PA conduit } & 19 & 5 & 3.4 & MS/AA & & \\
\hline & 20 & 7 & 3.4 & MS/AA & & $\dagger$ \\
\hline & 21 & 10 & 4.8 & MS/AS & & \\
\hline & 22 & 7 & 3.1 & MS/AS & & \\
\hline & 23 & 4 & 3 & MA/AA & & \\
\hline & 24 & 6 & 3.2 & $\mathrm{MS} / \mathrm{AA}$ & Atrial septectomy & \\
\hline & 25 & 7 & 3 & MS/AA & & \\
\hline & 26 & 5 & 2.9 & MS/AA & & \\
\hline & 27 & 3 & 3.4 & $\mathrm{MS} / \mathrm{AA}$ & & \\
\hline & 28 & 5 & 3.1 & $\begin{array}{l}\text { TA Ilc, restrictive VSD, } \\
\text { hypoplastic aortic } \\
\text { arch }\end{array}$ & & \\
\hline & 29 & 3 & 3.1 & $\begin{array}{l}\text { TA Ilc, restrictive VSD, } \\
\text { hypoplastic aortic } \\
\text { arch }\end{array}$ & & \\
\hline & 30 & 39 & 4.1 & SV & Atrial septectomy & \\
\hline & 31 & 5 & 3.3 & MS/AS & & \\
\hline & 32 & 6 & 3.4 & $\mathrm{MS} / \mathrm{AA}$ & & \\
\hline Median (quartile) & & $6[5 ; 7]$ & $3.3[3.1 ; 3.4]$ & & & \\
\hline$P$ value & & $P=.370$ & $P=.529$ & & & \\
\hline
\end{tabular}

$\overline{A A}$, Aortic atresia, $A S$, aortic stenosis; $B T$, Blalock-Taussig; $M A$, mitral atresia; $M S$, mitral stenosis; $P A$, pulmonary artery; $P F O$, patent foramen ovale; $R V$, right ventricle; $S L L$, situs solitus L-looped ventricles, left-sided position of the aorta; $S V$, single ventricle; TA, tricuspid atresia; TAPVC, total anomalous pulmonary venous connection; TGA, transposition of great arteries; VSD, ventricular septal defect.

Serum creatinine, troponine T levels: Maximum levels during the first 5 postoperative days were recorded.

Need for epinephrine: Highest dosage of epinephrine necessary during the first 5 days was recorded.

Respiratory parameters measured included:

$\mathrm{Po}_{2}, \mathrm{PCO}_{2}, \mathrm{O}_{2}$ saturation: Mean values of the recorded levels were calculated over 24 hours.

Additionally the $\mathrm{FIO}_{2}$ necessary to reach these levels was examined and compared.
After 3 months a catheterization laboratory study was done in all surviving patients (Table 3). The following data were compared: end-diastolic ventricular pressure, $\mathrm{dp} / \mathrm{dt}$, and $\mathrm{Qp} / \mathrm{Qs}$ ratio.

Although the study has a retrospective character, all data were obtained in a prospective way.

\section{Statistics}

Statistical analyses were based on the principle of intention to treat. Otherwise the results would be biased by the loss of good values from patients leaving the hospital and bad values from 
Table 2. Postoperative parameters: Obtained during the first 5 postoperative days in the intensive care unit

\begin{tabular}{|c|c|c|c|}
\hline & $\begin{array}{l}\text { BT shunt (median } \\
\text { [quartiles]) }\end{array}$ & $\begin{array}{c}\text { RV-PA conduit } \\
\text { (median [quartiles]) }\end{array}$ & $P$ value \\
\hline Troponin T (ng/mL) (max. level) & $1.8[0.96 ; 2.91]$ & $3.66[2.66 ; 4.81]$ & .001 \\
\hline Serum creatinine (mg/100 mL) (max. level) & $0.99[0.83 ; 1.11]$ & $0.89[0.8 ; 0.96]$ & .210 \\
\hline Decrease in serum lactate (hours to normalize) & $25[13 ; 32]$ & $22[14 ; 33]$ & .494 \\
\hline Epinephrine (max. dose) $\left(\mu \mathrm{g} \cdot \mathrm{kg}^{-1} \cdot \min ^{-1}\right)$ & $0.09[0.06 ; 0.2]$ & $0.07[0.05 ; 0.1]$ & .111 \\
\hline Urine output day $1\left(\mathrm{~mL} \cdot \mathrm{kg}^{-1} \cdot \mathrm{h}^{-1}\right)$ & $4.31[3.43 ; 5.16]$ & $4.37[3.33 ; 5.38]$ & .894 \\
\hline Urine output day $3\left(\mathrm{~mL} \cdot \mathrm{kg}^{-1} \cdot \mathrm{h}^{-1}\right)$ & $6.08[3.93 ; 7.27]$ & $6.14[5.16 ; 7.22]$ & .436 \\
\hline Urine output day $5\left(\mathrm{~mL} \cdot \mathrm{kg}^{-1} \cdot \mathrm{h}^{-1}\right)$ & $4.60[3.55 ; 5.56]$ & $5.41[4.67 ; 6.72]$ & .033 \\
\hline $\mathrm{P}_{2}$ day 1 & $37[33.97 ; 40.34]$ & $35.75[32.72 ; 40.46]$ & .436 \\
\hline $\mathrm{Po}_{2}$ day 3 & $41.5[38.85 ; 44.21]$ & $39.39[36.15 ; 41.65]$ & .160 \\
\hline $\mathrm{Po}_{2}$ day 5 & $40.45[38.71 ; 43.64]$ & $39.53[38.31 ; 42.04]$ & .447 \\
\hline $\mathrm{PCO}_{2}$ day 1 & $37.41[35.83 ; 38.82]$ & 34.53 [31.19;37.23] & .037 \\
\hline $\mathrm{PCO}_{2}$ day 3 & $38.1[36.55 ; 41.25]$ & $36.26[32.29 ; 39.34]$ & .098 \\
\hline $\mathrm{PcO}_{2}$ day 5 & $39.15[35.43 ; 43.46]$ & $38.81[35.28 ; 42.79]$ & .939 \\
\hline $\mathrm{FlO}_{2}$ day 1 & $0.41[0.36 ; 0.62]$ & $0.64[0.47 ; 0.79]$ & .042 \\
\hline $\mathrm{FlO}_{2}$ day 3 & $0.34[0.3 ; 0.45]$ & $0.5[0.37 ; 0.61]$ & .059 \\
\hline $\mathrm{FlO}_{2}$ day 5 & $0.3[0.37 ; 0.5]$ & $0.4[0.34 ; 0.51]$ & .163 \\
\hline
\end{tabular}

$B T$, Blalock-Taussig; $P A$, pulmonary artery; $R V$, right ventricle.

patients who died. During postoperative days 2 to 5 instances of missing data were replaced by the last available value (last observation carried forward). During follow-up missing data due to cardiac-related death were replaced by the worst available value (worst case). For those patients, missing data in the parameter "hospital stay" were replaced by the longest possible observation time (ie, 90 days).

Data evaluation was purely descriptive without adjustment of the $P$ values. Consequently, significances at $P<.05$ reflect the probability of differences, which can be best used for generating hypotheses but do not prove them. As nearly all data were not normally distributed (Shapiro Wilk test), all metric and ordinal variables were analyzed with the Mann-Whitney $U$ test (differences between BT shunt group and RV-PA conduit group). For 2 $\times 2$ tables Fisher's exact test was used.

\section{Results}

Comparison of the hemodynamic parameters showed a remarkably higher diastolic blood pressure in the RV-PA conduit group during the first 5 postoperative days (AUC days 1 to 5 and every single day: $P<.001$ ) (Figure 1 ). Systolic blood pressure tended also to higher levels (Figure 1) (AUC days 1 to $5: P=.138$; day $1: P=.217$; day $3: P$ $=.044$; day $5: P=.239$ ). We noted a trend toward lower postoperative levels of creatinine, greater urine output, lower left atrial pressure, and faster normalization of increased serum lactate levels in group 2. These and other important postoperative parameters are shown in Table 2.

\section{Outcome}

In-hospital survival in group 1 was $72 \%$ (13/18; two-tailed 95\% confidence interval: $46.5 \%, 90.3 \%$ ). Patients 5 and 15 died on postoperative days 4 and 31 due to low cardiac output. Patient 10 died of rupture of the native aorta some days after successful cardiopulmonary resuscitation follow-
Table 3. Cardiac catheterization data: Obtained at the age of 3 months, immediately before the bidirectional Glenn procedure

\begin{tabular}{lccc}
\hline & & Group 2 & \\
& $\begin{array}{c}\text { Group 1 (BT shunt): } \\
\text { Median [quartiles] }\end{array}$ & $\begin{array}{c}\text { (RV-PA conduit): } \\
\text { Median [quartiles] }\end{array}$ & $\begin{array}{c}\boldsymbol{P} \\
\text { value }\end{array}$ \\
\hline Saturation SVC (\%) & $51[43 ; 53]$ & $49[43 ; 53]$ & .682 \\
Saturation aorta (\%) & $81[78 ; 86]$ & $74[72 ; 79]$ & .036 \\
PAP (mm Hg) & $14[14 ; 17]$ & $13[12 ; 17]$ & .415 \\
Qp/Qs & $1.6[1.2 ; 1.6]$ & $0.9[0.8 ; 1]$ & .005 \\
EDP & $12[10 ; 16]$ & $11[8 ; 14]$ & .381 \\
dp/dt $\left(\mathrm{mm} \mathrm{Hg} / \mathrm{s}^{2}\right)$ & $776[615 ; 907]$ & $955[773 ; 1110]$ & .018 \\
\hline
\end{tabular}

$B T$, Blalock-Taussig; $d p, d t$, rate of pressure rise; $E D P$, end-diastolic pressure; $P A$, pulmonary artery; $P A P$, pulmonary artery pressure; $Q p / Q s$, pulmonary/systemic flow ratio; $R V$, right ventricular; $S V C$, superior vena cava.

ing ventricular fibrillation. Child 6 died of thrombotic occlusion of the BT shunt $(3.5 \mathrm{~mm}) 5$ days after surgery; child 8 died of cardiac failure after 3 weeks and several systemic infections (Table 1).

In-hospital survival in group 2 was 93\% (13/14; twotailed 95\% confidence interval: $66.1 \%, 99.8 \%$ ). After 3 uneventful postoperative days and immediately after delayed chest closure, patient 20 experienced a severe drop in pulmonary blood flow, characterized by low oxygen saturation and high $\mathrm{CO}_{2}$ levels, although ventilatory parameters remained unchanged. This state was resistant to any treatment including reopening of the chest and replacement of the RV-PA conduit by a 4-mm BT shunt (Table 1).

\section{Intensive Care Data}

All patients in group 1 had a delayed sternal closure at a mean interval of $4.37 \pm 1.45$ days. Encouraged by the stable postoperative performance of the RV-PA conduit patients, 


\section{BT shunt group}

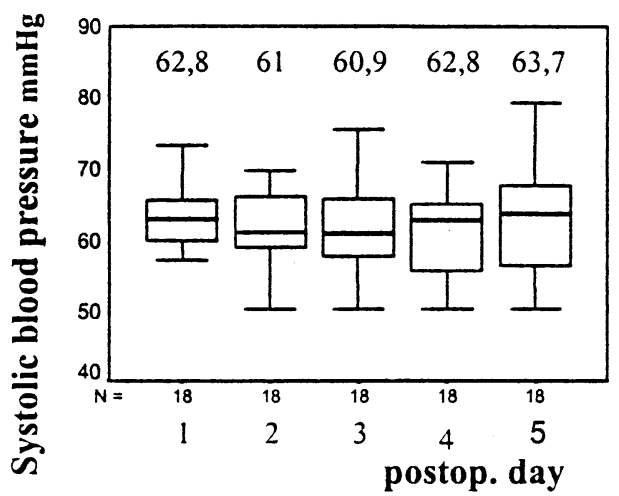

BT shunt group

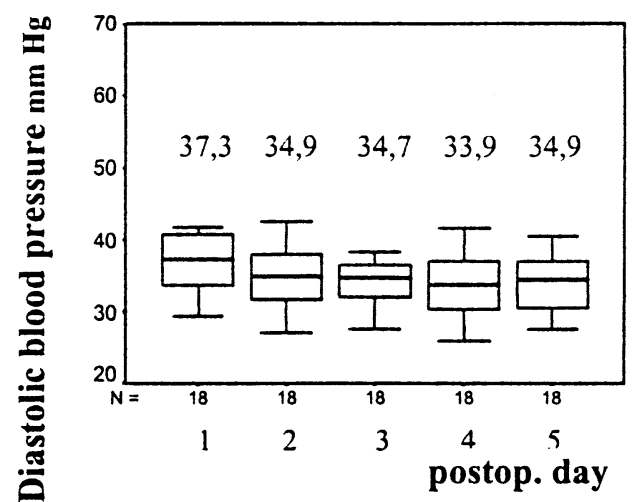

\section{RV-PA conduit group}

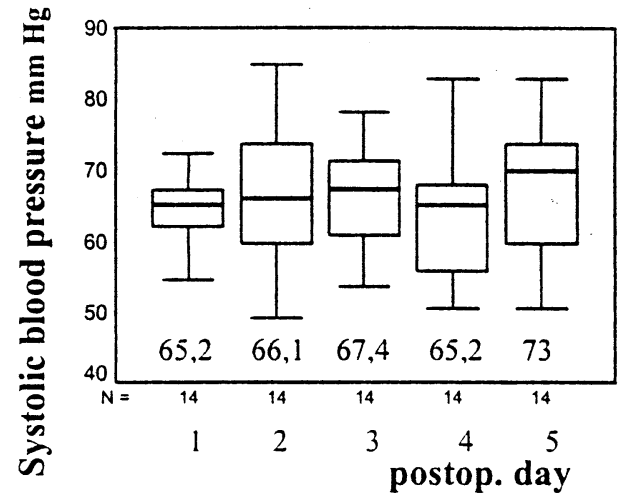

RV-PA conduit group

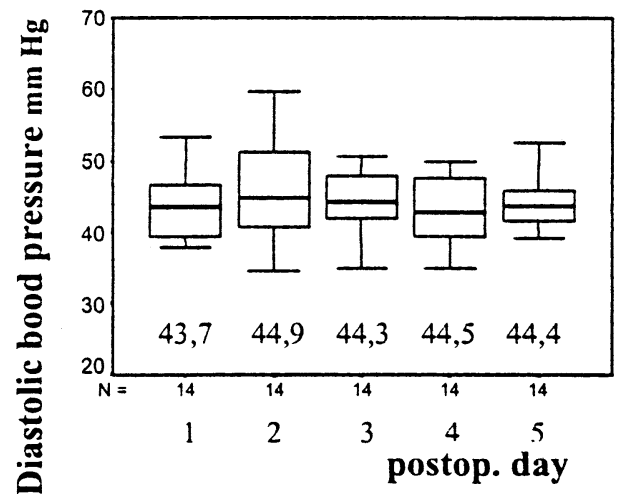

Figure 1. Systolic and diastolic blood pressure: median values from blood pressures recorded hourly during the first 5 postoperative days. Numbers within the diagrams show median values of the whole group.

we started primary chest closure in November 2001. This could be achieved in 7 of 8 patients. According to this, no important differences in hemodynamic and respiratory parameters were noticed.

Median postoperative stay at the ICU was not significantly different between both groups: 17 [12; 53] versus $16[10 ; 21]$ days $(P=.370)$. The postoperative intensive care management in all patients was done according to our standards. The goals were to achieve $\mathrm{PO}_{2}$ and $\mathrm{PCO}_{2}$ values around $40 \mathrm{~mm} \mathrm{Hg}$, adequate systemic perfusion, and avoidance of metabolic acidosis (lactate $<2 \mathrm{mmol} / \mathrm{L}$ ). All patients routinely received amrinone $(10 \mu \mathrm{g} / \mathrm{kg} / \mathrm{min})$ and dopamine $(3 \mu \mathrm{g} / \mathrm{kg} / \mathrm{min})$. Epinephrine was added individually until a satisfactory blood pressure and cardiac output was achieved.
Major complications in the ICU were: increased pulmonary vascular resistance causing severe cyanosis, requiring treatment with prostacyclin or nitric oxide, in 4 patients (1 in group 1; 3 in group 2); sepsis in 3 (1 in group 1; 2 in group 2); and early bleeding, requiring surgical treatment in 1 patient in group 1. Only 1 patient (in group 2) had a significant nonsustained arrhythmia (junctional ectopic tachycardia), which was treated with cooling and sedacorone for 3 days. All patients had Holter recordings before discharge and showed no arrhythmia.

Between stage I and stage II 3 children in group 1 died. Two went into an irreversible circulatory collapse after a short episode of diarrhea, and 1 had multiple extracardiac anomalies including malrotation of the gut causing ileus. The other 10 patients underwent a successful stage II pal- 
liation (bidirectional Glenn shunt at a median age of 92 [85; 101] days). There were no late deaths in group 2: 13 patients had already a successful stage II operation at a median age of $101[96 ; 120]$ days.

\section{Cardiac Catheterization Data}

At the age of 3 months, 10 of 18 patients in group 1 and 13 of 14 patients in group 2 underwent a diagnostic cardiac catheterization before the stage II procedure (Table 3). Two patients in group 1 and 2 patients in group 2 had a significant coarctation, with a gradient across the aortic arch of more than $25 \mathrm{~mm} \mathrm{Hg}$, which was successfully treated by balloon dilatation.

\section{Discussion}

After stage I Norwood palliation, systemic and pulmonary circulations are perfused in parallel and the cardiac output is distributed between these 2 beds. ${ }^{4}$ A modified BT shunt leads to continuous shunting during systole and diastole into the pulmonary arteries. With a progressive drop in pulmonary vascular resistance postoperatively, the shunt volume increases, causing diastolic runoff and low diastolic pressure, and thus low coronary artery perfusion pressure. ${ }^{5,6}$ Echocardiographically, diastolic reversal of flow in the aortic arch and descending aorta as a consequence of high Qp/Qs has been described. ${ }^{7}$ Hemodynamic instability, as well as early and late death, has been attributed to this mechanism. In this series of patients, group 2 (with RV-PA conduit) had higher diastolic blood pressures on postoperative days 1 to 5 than patients with BT shunts, although there was no important difference in systolic blood pressure. Therefore, we presume that coronary artery perfusion pressure and blood flow to the myocardium were better in group 2. Apart from higher mean arterial blood pressure, better cardiac function could also be a reason for the lower maximum dose of epinephrine necessary in group 2 .

$\mathrm{PO}_{2}$ levels on postoperative days 1 to 5 were not different (AUC days 1 to 5: $P=.239$ ), which was probably the result of different ventilation strategies to meet the goal of $\mathrm{Po}_{2}$ levels between 35 and $45 \mathrm{~mm} \mathrm{Hg}$. However, to achieve these $\mathrm{Po}_{2}$ levels in group 2, higher $\mathrm{FIO}_{2}$ (day 1: $P=.042$ ) and lower $\mathrm{CO}_{2}$ levels (day 1: $P=.037$ ) were necessary. This accounts for patients with delayed and primary chest closure as well.

These data provide evidence that pulmonary blood flow in the first 5 postoperative days was lower (but sufficient) in the group with an RV-PA conduit (group 2). Together with higher diastolic and mean arterial pressures, more efficient and stable hemodynamics were established.

The use of valved and nonvalved conduits was first described by Norwood and colleagues ${ }^{8}$ and recently reported again by Kishomoto and colleagues, ${ }^{9}$ who found markedly increased diastolic pressures, improved systemic perfusion, and more stable postoperative circulation. Both reports, however, were small series with 6 patients (4 survivors) and 7 patients (4 survivors), respectively, presenting little data of the early postoperative period. In these studies there was obviously 1 death related to early stenosis of the RV-PA conduit.

Although we documented reduced pulmonary blood flow compared with patients with a BT shunt, we noticed no significant conduit stenosis in the first 3 months after the operation. It is the policy of our institution to perform routine cardiac catheterization at 3 months of age, followed by stage II surgery (bidirectional Glenn shunt). Reduced pulmonary blood flow may cause impaired growth of the pulmonary vessels. We did not encounter any significant problems at stage II in any of the 13 patients in group 2 who underwent this procedure.

Of course, a lower Qp/Qs could also be achieved by smaller BT shunts (eg, 3-mm instead of 3.5-mm shunts). However, this would certainly increase the risk for shunt thrombosis.

Concerns have been raised about performing a ventriculotomy in an univentricular heart in terms of impaired ventricular function and generation of arrhythmias. As a matter of fact, the maximum troponine $\mathrm{T}$ level measured 1 hour postoperatively was higher in group 2 (BT shunt: 1.8 [0.96; 2.91]; RV-PA conduit: 3.66 [2.66; 4.81]; $P=.001$ ), most likely caused by the ventriculotomy in this group. Assessment of ventricular function by echocardiography in these patients is rather difficult, so we used dp/dt measurements obtained during cardiac catheterization 3 months after initial palliation. There were clearly better values in the RV-PA conduit group as shown in Table $3(P=.018)$. This could be attributed to reduced workload of the right ventricle because of less Qp/Qs $(P=.005)$ as well as to improved coronary perfusion due to higher diastolic pressures.

The ventriculotomy as well as the free pulmonary regurgitation of the nonvalved conduit seemed to be well tolerated. The only arrhythmia, noted in 1 patient in group 2, was junctional ectopic tachycardia, most likely unrelated to the ventriculotomy and limited to the early postoperative period.

\section{Conclusions}

Postoperative hemodynamics after a Norwood procedure with an RV-PA conduit are different from those with a modified BT shunt. Higher diastolic blood pressures and lower Qp/Qs ratios are associated with a more stable and efficient systemic circulation. Pulmonary perfusion restricted to systole leads to a lower Qp/Qs ratio and demands more intensive ventilatory support during the first postoperative days. Concerns about free pulmonary regurgitation and worsening effects of a ventriculotomy could not be proved.

The ventricular performance is obviously better in RV-PA conduit patients than in BT shunt patients. This 
means that the local lesion by a small ventriculotomy is outweighed easily by reduced volume load and better coronary perfusion.

\section{Limitations}

Encouraged by the stable postoperative course of the first patients, we did not perform a randomization between both operative techniques. Therefore, we cannot rule out that our increased experience with the postoperative management had a positive impact on our results.

\section{References}

1. Pearl JM, Nelson DP, Schwartz SM, Manning PB. First-stage palliation for hypoplastic left heart syndrome in the twenty-first century. Ann Thorac Surg. 2002;73:331-9.

2. Kern JH, Hayes CJ, Michler RE, Gersony WM, Quaegebeur JM. Survival and risk factor analysis for the Norwood procedure for hypoplastic left heart syndrome. Am J Cardiol. 1997;80:170-4.
3. Mahle WT, Spray TL, Gaynor JW, Clark BJ 3rd. Unexpected death after reconstructive surgery for hypoplastic left heart syndrome. Ann Thorac Surg. 2001;71:61-5.

4. Barnea O, Austin EH, Richman B, Santamore WP. Balancing the circulation: theoretic optimization of pulmonary/systemic flow ratio in hypoplastic left heart syndrome. J Am Coll Cardiol. 1994;24:1376-81.

5. Mosca RS, Bove EL, Crowley DC, Snadhu SK, Schork MA, Kulik TJ. Hemodynamic characteristics of neonates following first stage palliation for hypoplastic left heart syndrome. Circulation. 1995;92:SII26771.

6. Charpie JR, Dekeon MK, Goldberg CS, Mosca RS, Bove EL, Kulik TJ. Postoperative hemodynamics after Norwood palliation for hypoplastic left heart syndrome. Am J Cardiol. 2001;87:198-202.

7. Rychik J, Bush DM, Spray TL, Gaynor JW, Wernovsky G. Assessment of pulmonary/systemic blood flow ratio after first-stage palliation for hypoplastic left heart syndrome: development of a new index with the use of Doppler echocardiography. J Thorac Cardiovasc Surg. 2000; 120:81-7.

8. Norwood WI, Lang P, Hansen DD. Physiologic repair of aortic atresiahypoplastic left heart syndrome. N Engl J Med. 1983;308:23-6.

9. Imoto Y, Kado H, Shiokawa Y, Minami K, Yasui H. Experience with the Norwood operation without circulatory arrest. J Thorac Cardiovasc Surg. 2001;122:879-82.

\section{Bound volumes available to subscribers}

Bound volumes of The Journal of Thoracic and Cardiovascular Surgery are available to subscribers (only) for the 2003 issues from the Publisher, at a cost of $\$ 134.00$ for domestic, $\$ 165.85$ for Canadian, and $\$ 155.00$ for international subscribers for Vol 125 (January-June) and Vol 126 (July-December). Shipping charges are included. Each bound volume contains a subject and author index and all advertising is removed. The binding is durable buckram with the Journal name, volume number, and year stamped in gold on the spine. Payment must accompany all orders. Contact Mosby, Subscription Customer Service, 6277 Sea Harbor Dr, Orlando, FL 32887, USA; phone 800-654-2452 or 407-345-4000.

Subscriptions must be in force to qualify. Bound volumes are not available in place of a regular Journal subscription. 